\title{
Management of Tethered Cord Syndrome in Adults: Experience of 23 Cases
}

\author{
Ozden Erhan SOFUOGLU*, Anas ABDALLAH*, Erhan EMEL, Ali Ender OFLUOGLU, Muslum GUNES, \\ Betul GULER
}

Bakirköy Research and Training Hospital for Neurology Neurosurgery, and Psychiatry, Department of Neurosurgery, Istanbul, Turkey

"Ozden Erhan SOFUOGLU and Anas ABDALLAH contributed equally to this work.

\section{ABSTRACT}

AIM: Tethered cord syndrome (TCS) is rarely diagnosed in adults. It is a complex clinicopathological entity that remains poorly understood. In this study, clinical outcomes of 23 consecutive congenital TCSs diagnosed in adults have been evaluated to establish a standard approach to treat congenital TCS diagnosed in adults.

MATERIAL and METHODS: Medical records were retrospectively reviewed in 73 cases of TCS who were underwent surgery in our hospital, between 2005 and 2014. Cases which diagnosed and treated surgically in adults (patient age > 18 years) were included in this study.

RESULTS: Twenty-three adult cases of TCSs were treated surgically and 15 of them were female and 8 were male. The mean age was $30.3 \pm 10.7$ years. The mean follow-up period was $75.6 \pm 40.5$ months. The most common complaint was low back pain. The most common findings in the neurological examinations were muscular weakness and urinary incontinence. The most common co-malformations were diastematomyelia and vertebral fusion anomalies. Conus medullaris was mostly terminated at the L5 level. Detethering procedure was carried out in $87 \%$ of patients and bony septum resection without detethering was applied in $13 \%$. Laminoplasty was performed only in $39.1 \% .60 .9 \%$ of patients were recovered good. $34.8 \%$ of patients were improved. The most common complication was cerebrospinal fluid leakage.

CONCLUSION: Despite the good results obtained in our surgical interventions for symptomatic TCS in adults, tethered cord releasing is complex procedure and has serious complications. Therefore, it is suggested to plan surgery according to symptoms emphasized with full neurological examination, craniospinal imaging and urodynamic tests.

KEYWORDS: Tethered cord syndrome, Dysraphic lesions, Scoliosis, Diastematomyelia, Laminoplasty, Intraoperative neurophysiological monitoring, Urodynamic test

\section{INTRODUCTION}

$\mathrm{T}$ Tethered cord syndrome (TCS) is a deterioration involving an abnormal stretching of the tethered spinal cord, the ascent of which is limited and is disproportionate to the growth of the spinal column $(9,13)$. TCS is not a rare pathological disorder particularly in developing countries. This congenital syndrome usually associates to other syndromes may develop in children who are born to mothers suffered from folic acid deficiency. In contrast, TCS is rarely diagnosed in adults as well as it is a complex clinicopathological entity that remains poorly understood.

The incidence of neural tube defects is $0.17-6.39$ per 1000 live births worldwide (2). TCS is one of the common spinal dysraphic lesions which have been reduced in developed countries due to supplementation of folic acid during pregnancy and prenatal diagnosis of dysraphic malformations 
almost leading to termination of the pregnancy. Presenting symptoms due to a congenital TCS (such as; back pain, leg weakness, foot deformity, scoliosis, sensory loss, and/or bowel or bladder dysfunction) most common occur in children, but in many adult patients, the diagnosis is not established until symptoms manifest.

Several pathological conditions including fatty and thickened filum terminale, lipomyelomeningocele, meningocele, split cord malformation, and post-repair myelomeningocele may be responsible for TCS (5). It has been well established that children involved with TCS, whether symptomatic or otherwise, early surgical intervention (detethering) of congenital TCS in children prevents additional neurosurgical deficits $(4,9,11)$. With early diagnosis of these conditions, however, there is an ongoing debate of whether asymptomatic adult patients with a TCS should undergo prophylactic surgery (9).

According to Rajpal et al. with advancing age of the patients who involved to congenital TCS, these patients have an increased risk of developing new neurological deteriorations (14), therefore, they suggest surgery for adult patients with TCS to protect patients from new neurological deficits which may be permanent. Despite the management of congenital TCS diagnosed in adulthood remains controversial, results of recent clinical studies of surgical intervention in adults are encouraged $(7,9,12,14,19)$. The question here, how can neurosurgeons manage this complex entity to protect the patients from new deficits and keep their neurological functions intact? Herein, the surgical treatment outcomes of 23 consecutive congenital TCSs diagnosed in adults have been evaluated to find out the perfect (standard protocol) management for TC in adults (according to the authors here).

\section{MATERIAL and METHODS}

This retrospective, randomized study was approved by the medical ethics committee of our hospital. Written informed consent was obtained from all patients for publication of their cases and accompanying images.
Medical records were retrospectively reviewed in 73 cases of congenital TCS who were treated surgically in our hospital at department of neurosurgery, between 2005 and 2014. TCS cases which diagnosed and treated surgically in adults (patient age $>18$ years) were included in this study. The longterm clinical outcomes were evaluated retrospectively using patient complaints, the periods of first complaint and surgery, localizations, co-malformations, magnetic resonance imaging (MRI) findings, recurrence rate and complications. All patients underwent a hemilaminectomy, laminectomy or laminotomy before neurosurgical bony or fibrous septums removal then detethering filum terminale. To avoid serious complications, intraoperative neurophysiological monitoring and laminoplasty were performed especially in recent four years. Postoperative outcomes have been evaluated using neurological scoring system which presented by Klekamp and Samii in 1993 (Table l) (8).

Data are expressed as mean \pm standard deviation (SD) values of the mean, median, and minimum-maximum. Differences among groups were assessed with one-way analysis of variance (ANOVA) using SPSS 21.0 statistical package. Differences were considered statistically significant when $\mathrm{p}<0.05$.

\section{Surgical Procedure}

Under general anesthesia and intraoperative neurophysiological monitoring (especially in recent four years) the patients are positioned prone using supporting roll on each side. The paramedian vertical midline incision between the superior and inferior laminas that detected via MRI (e.g. If conus medullaris at L5 level the incision would be extended between L4 to S1) was performed. After dissecting the paraspinal muscles [if the aim was to perform partial or total (complete) laminectomy, the dissection was done unilaterally, but if the surgeons were planning to perform laminoplasty, the dissection done bilaterally]. Hemilaminectomy, laminectomy or laminotomy (in cases of spina bifida occulta, defective laminotomy was used) was completed. If the purpose was laminoplasty, bilateral

Table I: Neurological Scoring System (8)

\begin{tabular}{cccccc}
\hline Score & Pain Intensity & $\begin{array}{c}\text { Sensory Disturbance, } \\
\text { Dysesthesias }\end{array}$ & Motor Weakness & Gait Ataxia & Sphincter Function \\
\hline 5 & None & Normal & Full power & Normal & Normal \\
\hline 4 & Slight, no medication & Present, not significant & $\begin{array}{c}\text { Movement against } \\
\text { resistance }\end{array}$ & Unsteady, no aid & $\begin{array}{c}\text { Slight disturbance, no } \\
\text { catheter }\end{array}$ \\
\hline 3 & $\begin{array}{c}\text { Tolerable w/ } \\
\text { medication }\end{array}$ & $\begin{array}{c}\text { Significant, function not } \\
\text { restricted }\end{array}$ & $\begin{array}{c}\text { Movement against } \\
\text { gravity }\end{array}$ & Mobile w/ aid & $\begin{array}{c}\text { Residual in urodynamic } \\
\text { studies, no catheter }\end{array}$ \\
\hline 2 & $\begin{array}{c}\text { Insufficient control w/ } \\
\text { medication }\end{array}$ & $\begin{array}{c}\text { Some restriction of } \\
\text { function }\end{array}$ & $\begin{array}{c}\text { Movement w/o gravity } \\
\text { funtention }\end{array}$ & Few steps w/ aid & Rarely incontinent \\
\hline 1 & $\begin{array}{c}\text { Severe despite } \\
\text { medication }\end{array}$ & $\begin{array}{c}\text { Severe restriction of } \\
\text { function }\end{array}$ & $\begin{array}{c}\text { Contraction w/o } \\
\text { movement }\end{array}$ & Standing w/ aid & Frequent catheter \\
\hline 0 & Incapacitating & Incapacitated function & Paralysis & Paralysis & Permanent catheter \\
\hline
\end{tabular}

*Modified according our protocol; w: with, w/o: without. 
laminotomy was performed using high-speed drills or kerrison rongeurs. Then, ligamentum flavum and the adipose tissue were removed. The spinal cord may continue until the S1 or S2 levels by giving some sacral rootlets, the laminectomy or laminotomy should be performed up to this level. The operative microscope is brought in over operation field. Thecal sac should be opened in the midline and tacked up bilaterally using strong sutures. After exposure of all nerve roots, filum terminale and arachnoid bands, the neurosurgeons select the filum terminale using the microscope (generally senior neurosurgeons select the filum terminale according to suspected of its structure). Filum terminale appears darker in color than nerve rootlets under the microscope. This aspect of filum terminale is related to its fibrovascular tag structure that contains a large vessel, which becomes smaller across through thecal sac $(10,16,18)$. On the other hand, this vessel is not a reliable landmark for filum terminale (because similar vessels can be found on the rootlets or no vessel may be seen on filum terminale). Therefore, the neurosurgeons checked it with probe of neurophysiological device. The rootlets at the sacral levels are directed to both sides and may be identified by their size, passing route and location. The arachnoid bands are attached to the thecal sac and rootlets. Both of the nerve rootlets and arachnoid bands are thin and white in color. To detect the place of untethering surgeons put probe of neurophysiological device on the posterior point of the filum terminale, after the save sign (the sign of the neurophysiological device means that the indicated structure is not neural structure) is taken. The rootlets are retracted laterally, then, filum terminale is coagulated and cut after the identification. All connective tissues attached to the caudal part of the spinal cord and conus medullaris should be released. After hemostasis using serum physiologic water, duraplasty is performed using 5.0 absorbable sutures (such as vicryl). In cases of bony septum (BS) or fibrous band (FB) (can detect via study craniospinal MRI), first, resection of BS or FB should be done before untethering conus medullaris. Three cases (13\%) of our series were resection of BS or FB enough to relief patients' complaints. In cases of dermal sinus, the tracts may be attached to the thecal sac, therefore, these structures should also be removed and duraplasty should be done if it was necessary. In cases of lipoma, cyst or other hamartomas that press on nerve rootlets and narrowing the thecal sac, hamartomas should be removed too. To avoid the serious complications and prevent retethering; lipomas should not be removed aggressively. This decision should be taken after the intraoperative evaluation. Keep the operation field clean and preserve cerebrospinal fluid (CSF) circulation between the neural elements.

\section{Illustrative Cases}

Case 1: A 61-year-old male was referred to our hospital with low back and right leg pains. He was experiencing trauma (failing) before 6 years. His neurological examination was intact; expect weakness in right leg distal muscle group of 4/5, L2-5 and $\mathrm{S} 1$ dermatomal hypoesthesia, neurogenic claudication and Babinski: bilateral indifferent. MRI demonstrated that diastematomyelia expends between both of L2 and L4. L3 and L4 vertebral fusion anomaly (block vertebra), at L3 level split cord malformation as bony septum and dermal sinus tract are apparent. Giant cyst extends between L1 and S2; spinal cord at S1-2 level (Figure 1A-C). Urodynamic study showed normocompliance normotonic bladder function. The patient underwent bony septum resection and duraplasty using total L3 and 4 laminoplasty, then cystectomy using total $\mathrm{S} 1$ laminoplasty. He made good recovery and was discharged after 3 days without any complication. The patient on his postoperative $48^{\text {th }}$ month physician visit was doing well.

Case 2: A 21-year-old female was referred to our hospital with low back and both legs pain for more than 5 years. In the last month her urinary incontinence developed. Her neurological examination was intact; expect rarely loss control of her urination. MRI showed that spinal cord terminates at L5 level (Figure 2). No additional malformation was detected in physical examination. The patient underwent tethered cord release using L5 laminoplasty. She made good recovery and was discharged after 2 days without any complication. The patient on her postoperative $10^{\text {th }}$ month physician visit was doing well.

\section{RESULTS}

Twenty-three cases of TCSs were treated surgically in fifteen female $(65.2 \%)$ and eight male $(34.8 \%)$ patients. Baseline clinical characteristics, co-malformations, treatment, outcomes and complications of treatment were given in Table II. The mean age was $30.3 \pm 10.7(18-61)$ years. The mean follow-up period was $75.6 \pm 40.5(10-127)$ months. The duration between the initial symptom and time of surgical intervention ranged between 4 months and 25 years with average of 6.3 years. The most common complaint was low back pain, which followed by legs pain and urinary \pm bowel incontinence (Table IV). The most common finding in the neurological examinations were urinary incontinence (seen in 12 patients) and motor weakness (seen in 12 patients), which were followed by hypoesthesia (seen in 8 patients) (Table V). Urodynamic test was performed in 19 patients which revealed on overactive detrusor muscle in 3 patients, post-void residual urine $(>100 \mathrm{ml})$ showed in 8 patients and normocompliance normotonic bladder function in 8 patients. The most associated malformations were diastematomyelia (seen in 10 patients) and vertebral fusion anomalies (seen in 10 patients), which were followed by split cord malformations (seen in 8 patients) (Table $\mathrm{VI}$ ). The most common level of conus medullaris was L5 level which was detected $34.8 \%$ of the patients. Detethering carried out in $87 \%$ of patients and bony septum resection without detethering applied in $13 \%$. Surgical approaches were laminoplasty (39.1\%), laminectomy (43.5\%) and hemilaminectomy (17.4\%). Surgical outcomes were divided in three groups; recovered good group which seen in $60.9 \%$ of our patients, improved group which was seen $34.8 \%$ of our series and worsened neurological deficits which was seen in one patient (Table III). The surgical morbidity rate is $4.3 \%$. The most common complications were CSF leakage (13\%) and surgical site infections (13\%). Pseudomeningocele was developed in one female patient 4 years after detethering surgery. All of these patients were successfully treated either conservatively or surgically. 

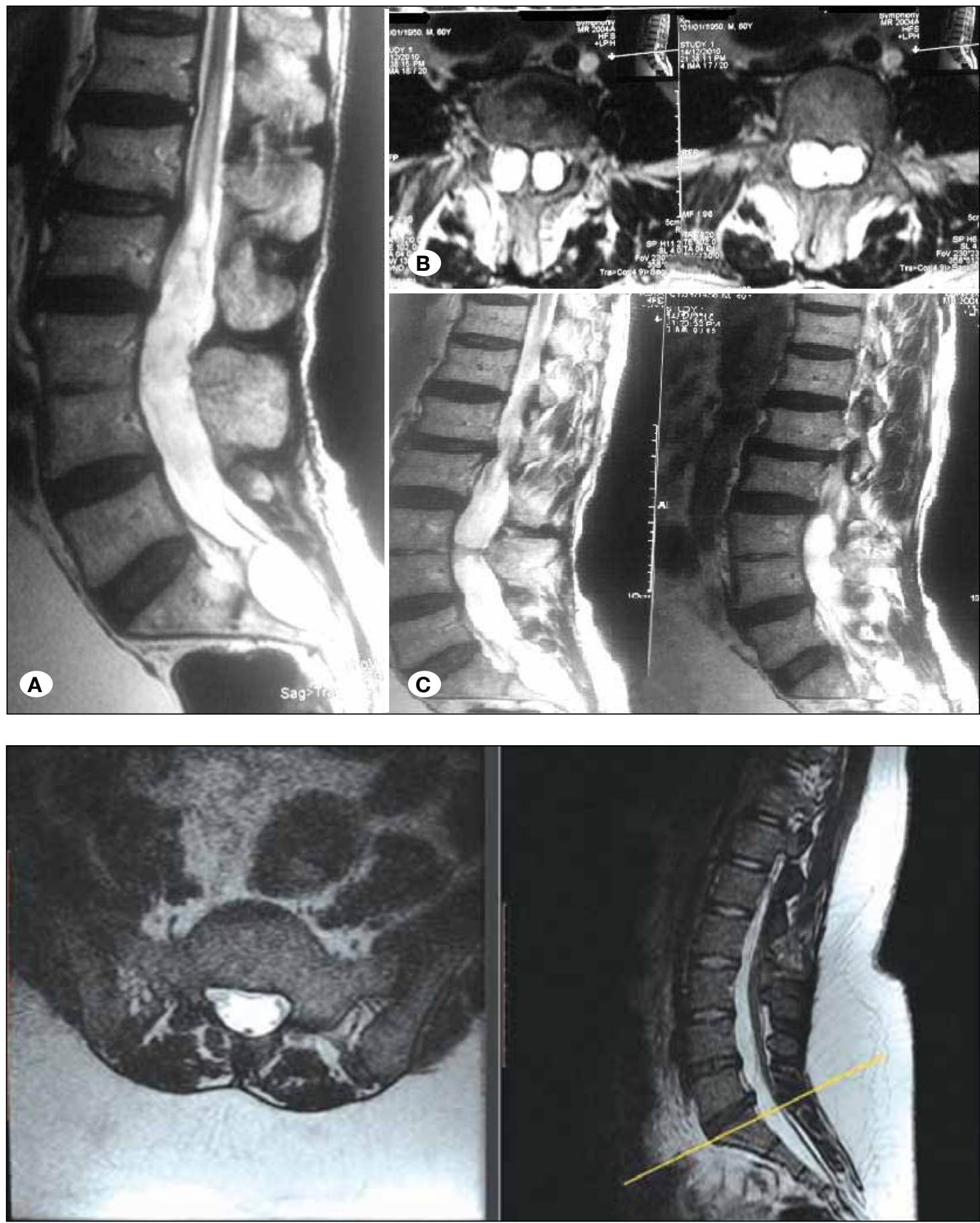

Figure 1: A 61-yearmale patient presented with numbness, low back and leg pain; A) Sagittal MRI demonstrated cyst extends between L1 and S2. Note that L3 and L4 vertebral fusion anomaly (block vertebra) is apparent; B) Axial MRI showed that diastematomyelia expends between both of L2 and L4. Note that split cord malformation as bony septum at L3 level, and dermal sinus tract are apparent; C) Sagittal MRI demonstrated that spinal cord terminates at S1-2 level.

Figure 2: A 21-yearold female was presented with low back and both legs pains for more than 5 years. Her neurological examination was intact; expect rarely loss control of her urination. MRI demonstrated that spinal cord terminates at L5 level.

\section{DISCUSSION}

The female preponderance in adult patients with TCS is well-established observation in all series reported before $(6,7,11,14)$. However, some authors reported a whole series of males such as article of Akay et al. who reported nine young males of SCMs (1). In our series, the female predominance of $5: 8(65.2 \%)$ was observed in our patients. Klekamp reported in his series that the female predominance was observed in $71.8 \%$ of his patients whom underwent detethering procedure (7).
The structure of filum terminale is especially important in the development of TCS. The recent studies $(10,18)$ such as; Tehli et al. (18) report, in their comparative study of histopathological analysis of filum terminale between TCS patients and normal human fetuses, that adipose tissue, fibrosis, hyalinization, and meningothelial proliferation were observed in filum terminale samples of TCS patients, while none of these findings were observed in normal fetal samples. Elastic fibers were present in all TCS specimens and the adult cadaver, but were not observed in fetuses $(10,18)$. Peripheral nerves, ganglion cells 


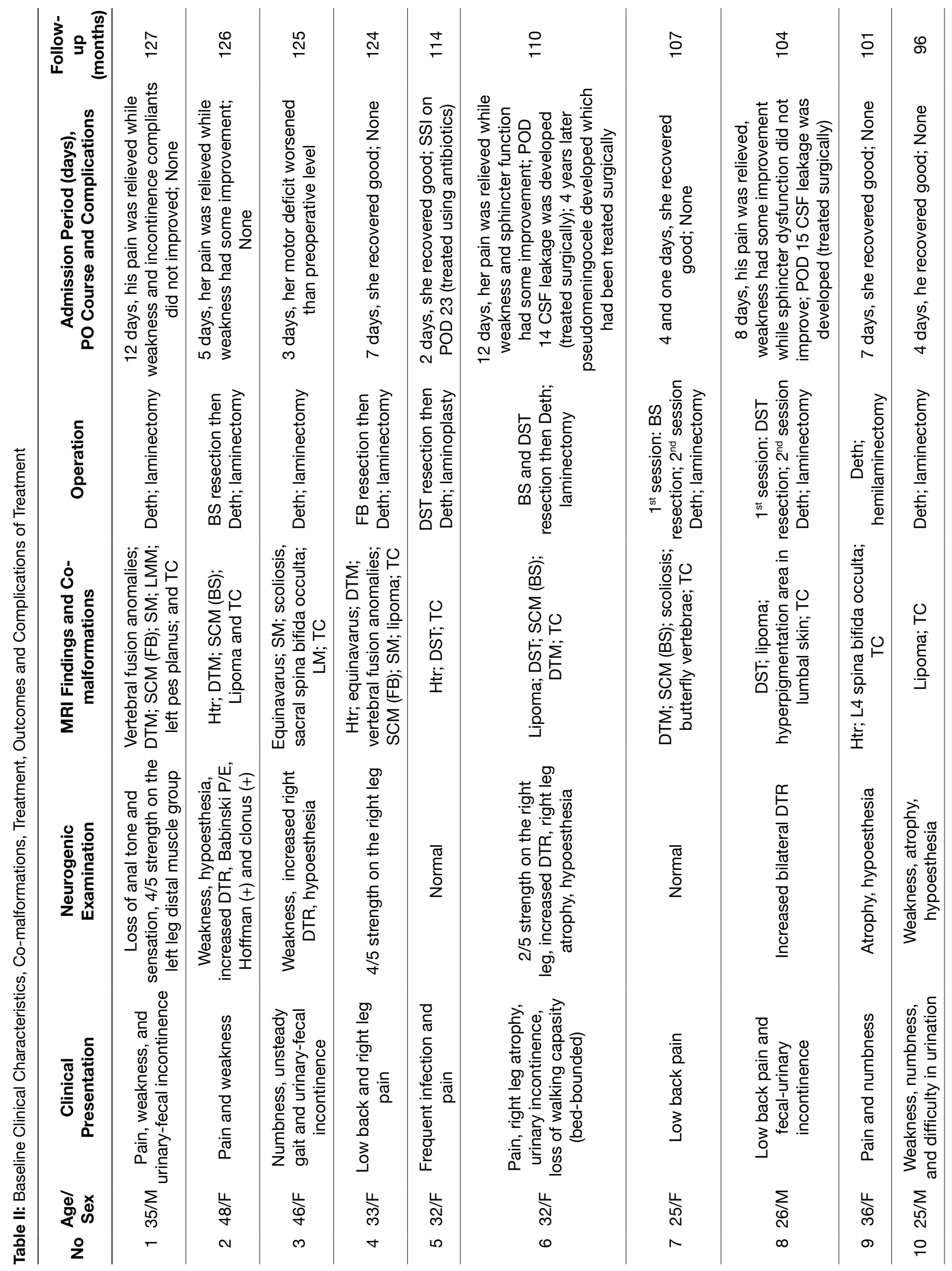




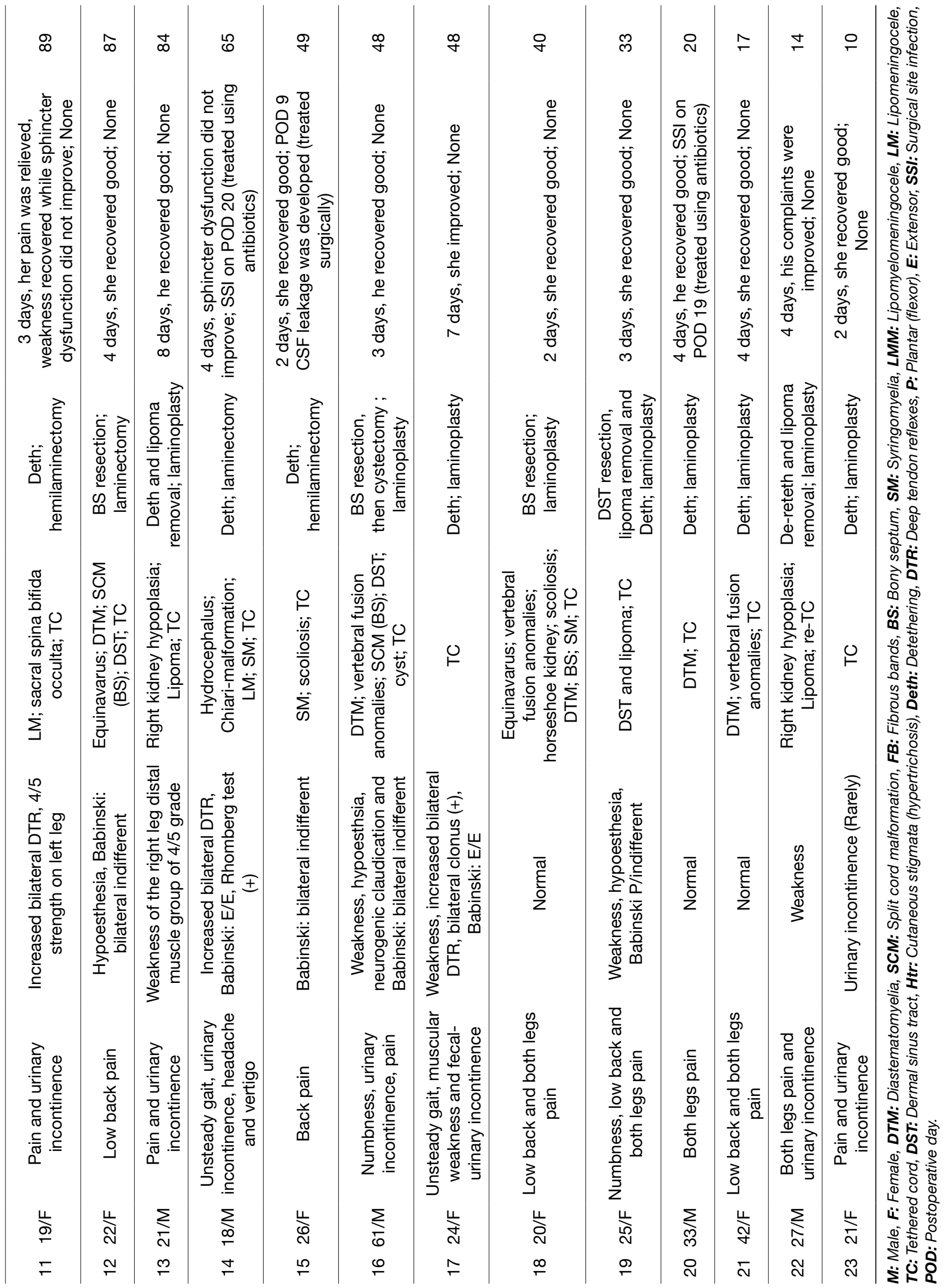


and ependymal cells were observed in normal human fetal filum terminale samples (18). Because these changes are not observed in fetuses, they suggest that this syndrome did not begin in intrauterine life (18).

Most adult patients experience tethered cord (TC) during normal daily activity or mild static neurological deficits in childhood. As a result of the development in imaging technologies, the number of adults in whom congenital TCS is diagnosed increases. However, adults compared with pediatric population may be denial of any significant symptoms and unwilling to visit their doctors, therefore, usually diagnosis of TCS in adults done after progressive scoliosis, foot deformities, leg length discrepancy, or muscular atrophy which may increase their chances of disability. In some cases, serious traumas such as traffic accident or failing as well as dynamic and static changes occur on spinal column (such as those happen in pregnancy) that may aggravate the degenerative processes and induce back and leg pains. In our series, the most common complaint was pain that was seen in 20 patients $(87 \%$ of our patients); 15 patients were experienced low back pain $(65.2 \%)$ and 13 patients were experienced legs pain (56.5\%). The pain was followed by bladder dysfunction and muscular weakness which were seen in 12 patients $(52.2 \%)$ of each (Tables II, IV). In TCS, stretching of the conus medullaris and nerve roots may induce back pain, leg weakness, foot deformity, scoliosis, sensory loss, and/or bowel or bladder dysfunction $(5,9,11,13)$. Untreated TCS can progress in $27.5 \%$, $40 \%$, and $60 \%$ of cases at 1,2 , and 5 years after diagnosis, respectively (13). In our institute, in the last 10 years 93 adult patients were diagnosed with TC after permanent or severe

Table III: Clinical Outcomes according to the Neurological Scoring System

\begin{tabular}{|c|c|c|c|c|c|c|}
\hline $\mathrm{No}^{\star \star *}$ & $\begin{array}{l}\text { Leg } \pm \text { Back Pain } \\
\text { Intensity Preop/ } \\
\text { Postop }\end{array}$ & $\begin{array}{c}\text { Sensory Disturbance, } \\
\text { Dysesthesias Preop/ } \\
\text { Postop }\end{array}$ & $\begin{array}{l}\text { Motor Weakness } \\
\text { Preop/Postop }\end{array}$ & $\begin{array}{l}\text { Gait Ataxia } \\
\text { Preop/Postop }\end{array}$ & $\begin{array}{l}\text { Sphincter } \\
\text { Function } \\
\text { Preop/Postop }\end{array}$ & $\begin{array}{l}\text { Surgical } \\
\text { Outcome }\end{array}$ \\
\hline 1 & $2 / 4$ & $5 / 5$ & $4 / 4$ & $4 / 4$ & $3 / 4$ & Improved \\
\hline 2 & $3 / 4$ & $4 / 4$ & $3 / 4$ & $4 / 4$ & $5 / 5$ & Improved \\
\hline 3 & $5 / 5$ & $2 / 3$ & $4 / 2$ & $2 / 3$ & $0 / 1$ & Worsened \\
\hline 4 & $3 / 5$ & $5 / 5$ & $4 / 5$ & $5 / 5$ & $5 / 5$ & Good recovery \\
\hline 5 & $4 / 5$ & $5 / 5$ & $5 / 5$ & $5 / 5$ & $5 / 5$ & Good recovery \\
\hline 6 & $2 / 4$ & $1 / 3$ & $2 / 2$ & $1 / 1$ & $2 / 4$ & Improved \\
\hline 7 & $2 / 5$ & $5 / 5$ & $5 / 5$ & $4 / 5$ & $5 / 5$ & Good recovery \\
\hline 8 & $3 / 5$ & $5 / 5$ & $5 / 5$ & $2 / 4$ & $0 / 1$ & Improved \\
\hline 9 & $3 / 5$ & $4 / 5$ & $5 / 5$ & $5 / 5$ & $5 / 5$ & Good recovery \\
\hline 10 & $5 / 5$ & $4 / 5$ & $4 / 5$ & $5 / 5$ & $3 / 4$ & Good recovery \\
\hline 11 & $4 / 5$ & $5 / 5$ & $4 / 5$ & $5 / 5$ & $1 / 2$ & Improved \\
\hline 12 & $1 / 4$ & $4 / 5$ & $5 / 5$ & $5 / 5$ & $5 / 5$ & Good recovery \\
\hline 13 & $2 / 5$ & $5 / 5$ & $4 / 5$ & $4 / 5$ & $2 / 4$ & Good recovery \\
\hline 14 & $4 / 5$ & $5 / 5$ & $5 / 5$ & $3 / 5$ & $1 / 3$ & Improved \\
\hline 15 & $2 / 5$ & $5 / 5$ & $5 / 5$ & $5 / 5$ & $5 / 5$ & Good recovery \\
\hline 16 & $2 / 5$ & $4 / 5$ & $4 / 5$ & $5 / 5$ & $3 / 5$ & Good recovery \\
\hline 17 & $3 / 4$ & $5 / 5$ & $3 / 5$ & $2 / 4$ & $3 / 4$ & Improved \\
\hline 18 & $1 / 5$ & $5 / 5$ & $5 / 5$ & $5 / 5$ & $5 / 5$ & Good recovery \\
\hline 19 & $2 / 5$ & $4 / 4$ & $4 / 5$ & $5 / 5$ & $5 / 5$ & Good recovery \\
\hline 20 & $1 / 4$ & $5 / 5$ & $5 / 5$ & $5 / 5$ & $5 / 5$ & Good recovery \\
\hline 21 & $1 / 4$ & $5 / 5$ & $5 / 5$ & $5 / 5$ & $5 / 5$ & Good recovery \\
\hline 22 & $2 / 4$ & $5 / 5$ & $4 / 5$ & $5 / 5$ & $2 / 3$ & Improved \\
\hline 23 & $2 / 5$ & $5 / 5$ & $5 / 5$ & $5 / 5$ & $2 / 5$ & Good recovery \\
\hline
\end{tabular}

** Case No in this table refere to the same case No in Table II. 
pain in their back and/or legs (incidentally) or in those experienced serious urological complaints. Only 23 adult patients $(24.7 \%)$ that diagnosed as symptomatic TC were treated surgically, after all investigations and full evaluation to clinical status of the patients.

Table IV: The Presenting Symptoms of 23 Adult TCS Patients

\begin{tabular}{lcc}
\hline Presenting Symptoms & $\begin{array}{c}\text { No of the } \\
\text { patients }\end{array}$ & Percentage \\
\hline Low back pain & 15 & $65.2 \%$ \\
\hline Leg pain & 13 & $56.5 \%$ \\
\hline $\begin{array}{l}\text { Bladder dysfunction } \\
\text { (incontinence or retention) }\end{array}$ & 12 & $52.2 \%$ \\
\hline Muscular weakness & 12 & $52.2 \%$ \\
\hline Numbness & 5 & $21.7 \%$ \\
\hline Unsteady Gait & 4 & $17.4 \%$ \\
\hline $\begin{array}{l}\text { Bowel dysfunction (fecal } \\
\text { incontinence) }\end{array}$ & 4 & $17.4 \%$ \\
\hline Muscular atrophy & 3 & $13 \%$ \\
\hline Lumbar swelling & 2 & $8.7 \%$ \\
\hline Frequent lumbar skin infection & 1 & $4.3 \%$ \\
\hline Headache & 1 & $4.3 \%$ \\
\hline Vertigo & 1 & $4.3 \%$ \\
\hline
\end{tabular}

Table V: The Clinical Findings in Neurological Examination of 23 Adult TCS Patients

\begin{tabular}{lcc}
\hline Clinical Findings & $\begin{array}{c}\text { No of the } \\
\text { patients }\end{array}$ & Percentage \\
\hline $\begin{array}{l}\text { Bladder dysfunction } \\
\text { (incontinence or retention) }\end{array}$ & 12 & $52.2 \%$ \\
\hline $\begin{array}{l}\text { Muscular weakness (motor } \\
\text { deficit) }\end{array}$ & 12 & $52.2 \%$ \\
\hline Hypoesthesia & 8 & $34.8 \%$ \\
\hline $\begin{array}{l}\text { Increased deep tendon reflex } \\
\text { Loss of anal tone and sensation }\end{array}$ & 5 & $21.7 \%$ \\
\hline fecal incontinence) & 4 & $17.4 \%$ \\
\hline Extensor or indifferent Babinski & $4 / 2$ & $17.4 \% / 8.7 \%$ \\
\hline Muscular atrophy & 3 & $13 \%$ \\
\hline Lumbar local tenderness & 3 & $13 \%$ \\
\hline Positive clonus & 2 & $8.7 \%$ \\
\hline Positive hoffman & 1 & $4.3 \%$ \\
\hline Normal clinical findings & 5 & $21.7 \%$ \\
\hline
\end{tabular}

The patients with tolerable pain which was seen in all of the adult patients with TCS in our series were treated conservatively, with close follow-up (by 3 months periods of follow-up) to avoid permanent new neurological deficits. The patients have to undergo full neurological examination especially those who experienced low back and legs pain associated with urination complaints, the most common clinical findings in our series are bladder dysfunction and muscular weakness which are seen in 12 patients of each $(52.2 \%)$. The pathological

Table VI: Co-Malformations that were Detected in 23 TCS Adult Patients

\begin{tabular}{|c|c|c|}
\hline Malformation & $\begin{array}{l}\text { No of the } \\
\text { patients }\end{array}$ & Percentage \\
\hline Conus medullaris (Tethered cord) & 23 & $100 \%$ \\
\hline At L2 level & 1 & $4.3 \%$ \\
\hline At L3 level & 3 & $13 \%$ \\
\hline At L4 level & 3 & $13 \%$ \\
\hline At L5 level & 8 & $34.8 \%$ \\
\hline At S1 level & 6 & $26.1 \%$ \\
\hline At S2 level & 2 & $8.7 \%$ \\
\hline Diastematomyelia & 10 & $43.8 \%$ \\
\hline Vertebral fusion anomalies & 10 & $43.8 \%$ \\
\hline Split cord malformation & 8 & $34.8 \%$ \\
\hline As Bony septum & 5 & $21.7 \%$ \\
\hline As Fibrous bands & 3 & $13 \%$ \\
\hline Lipoma & 8 & $34.8 \%$ \\
\hline Scoliosis & 5 & $21.7 \%$ \\
\hline Syringohydromyelia & 5 & $21.7 \%$ \\
\hline Dermal sinus tract & 5 & $21.7 \%$ \\
\hline $\begin{array}{l}\text { Foot anomalies (equinavarus, } \\
\text { pes planus) }\end{array}$ & 5 & $21.7 \%$ \\
\hline Hypertrichosis & 4 & $17.4 \%$ \\
\hline Lipomeningocele & 3 & $13 \%$ \\
\hline $\begin{array}{l}\text { Kidney malformations } \\
\text { (hypoplastic, horseshoe) }\end{array}$ & 3 & $13 \%$ \\
\hline Lipomyelomeningocele & 1 & $4.3 \%$ \\
\hline Mitral valve prolapse & 1 & $4.3 \%$ \\
\hline Chiari malformation & 1 & $4.3 \%$ \\
\hline Hydrocephalus & 1 & $4.3 \%$ \\
\hline Skin hyperpigmentation & 1 & $4.3 \%$ \\
\hline $\begin{array}{l}\text { Only tethered cord without } \\
\text { co-malformation }\end{array}$ & 2 & $8.7 \%$ \\
\hline
\end{tabular}


(abnormal) responses of all of deep tendon reflexes, Babinski reflex, clonus, and Hoffman sign which are noticed in 11 patients of our series $(47.8 \%)$ are important indicators to check-up the patient craniospinal MRI (Tables II, V). Because of the expected new neurological deficits in their age group are high, the surgical intervention rate was $100 \%$ (50 child was diagnosed with TCS) of all children and adolescents with TCS referred to us. Klekamp reported that 43 out of his 85 (50.8\%) adult patients with TC underwent detethering procedure (7).

Review of the literature suggests that the reversible symptoms associated with TCS are related to metabolic derangements and alterations in oxidative metabolism (20). All neuronal damages occur in TCS patients may not repair after surgical intervention, persisting of symptoms can vary depending on severity and duration between presentation and the initial treatment. If treated early, patients can recover from their neurological deficits. Chronic or excessive stretching of the spinal cord can lead to permanent disability. Although the duration between the initial symptom and time of surgery in our series ranged between 4 months and 25 years with average of 6.3 years, the early surgical intervention after increasing intensity of pain, or severity of complaints gave good results as recovered good was seen in $60.9 \%$ and improved group was seen $34.8 \%$. only one patient had worsened neurological deficits (Table III). Our good surgical outcomes were related to the full evaluation performed in all patients separately. The patients who were diagnosed with TC incidentally after moderate pain were closely followed-up and when their complaints started to be symptomatic and urological complaints were added to their clinical pictures urodynamic studies were reperformed and then a decision was made for surgical intervention.

Iskandar et al. (6) reported that untethering can improve in 22 of 27 patients (81.5\%) presenting with pain, 13 of 27 (48.1\%) patients with motor or sensory dysfunction, and 11 of 18 patients $(61.1 \%)$ with bowel and bladder disturbance. TC release and/or BS resection in our patients can improve and recover pain in $15.8 \%$ (3 out of 19 patients) and $84.6 \%$ (16 out of 19 patients), respectively. Muscular weakness recovered in 8 out of 12 our patients $(66.7 \%)$, unchanged in two, worsened and improved in one patient each. However, sensory disturbance remained unchanged in $50 \%$ (4 out of 8 patients) in our series. Bladder and bowel dysfunction improved, recovered and unchanged in $50 \%$ (6 out of 12 patients), $25 \%$ and $25 \%$, respectively. These surgical outcomes are better than those reported by Lee et al. (12) who found that surgical intervention can improve back and leg pain in $78 \%$ and $83 \%$ of patients, respectively. Motor weakness will stabilize or improve in only $27 \%$ and $64 \%$ of patients, respectively. Sensory deficits remained unchanged in $50 \%$ of patients. Urological abnormalities improved in $50 \%$ of patients undergoing detethering and remained stable in $45 \%$.

Solmaz et al. (16) reported in their results of the untethering procedure carried out in the pediatric population that neurological improvement was observed in $4(44.4 \%)$ of 9 children, while unchanged in the others. Urological disturbances improved in 2 (20\%) of 10 children (16).
Back pain was improved in all patients (16). These results show that our results were better. However, the complication rate in the same study (16) was less than our complication rate. CSF leakage was seen in $3(6.1 \%)$ of 49 their children versus $3(13 \%)$ of adult patients in our study. Solmaz et al. (16) reported no neurological deterioration or surgical site infection was recorded. Unfortunately, in our results surgical site infections were seen in $3(13 \%)$ patients. Pseudomeningocele was developed in one female patient 4 years after detethering surgery. Retethering was obsereved in one patient $(4.3 \%)$ of us, while Solmaz et al. (16) reported high retethering rate as $24.5 \%$ among children involved with TC.

The neurosurgical team here ought to use the same surgical procedure was described by Solmaz et al. (16) with some differences. In this article, laminoplasty and neurophysiological monitoring were the purpose of the surgery especially in last four years. Although a lot of approaches described for detethering procedure in adults such as; mini-open (minimal invasive), traditional open laminectomy or laminoplasty, A wide lumbosacral laminectomy is still the standard approach used to explore split cord malformation and to detether the filum terminale. In a comparison between laminoplasty (laminas were removed bilaterally using high-speed drill then after detethering or whatever the planned surgery was performed, laminas were sutured using a strong non-absorbable suture bilaterally to both lamina parts and interspinous ligaments cranially and caudally), hemilaminectomy and laminectomy in our series, the author found that laminoplasty is less than hemilaminectomy and laminectomy approaches in the length of stay at hospital with averages of $3.9 \pm 2.2(2-8)$ days, against $4 \pm 2.2(2-7)$ days, and $6.4 \pm 3.3$ (3-12) days, respectively. This difference was not significantly different $(p=0.57)$ and $(p=0.29)$, respectively (significance level was considered when $p<0.05$ ). On the other hand, three approaches did not affect the neurological outcomes and surgery-related complications.

Only 2 patients in our series were free of other malformations that associated with TC (Tables II, VI), therefore, the malformations in patients with classic symptoms of TCS have to aware the physicians to refer such patients to neurosurgeons. Split cord malformations are mainly associated with TCS in adults (1). Seven of 8 patients who had split cord malformation had been treated by bony septum (BS) or fibrous band (FB) resection, and only 4 of these seven needed to detethering procedure after this to relieve their pain or other complaints. In the rest three patients detethering procedure did not apply to avoid new neurological deficits. 2 out of 8 patients who had lipoma had been treated by removal of lipoma, and one else treated with cystectomy. 4 out of 5 patients presented with dermal sinus tract had been treated by resection it and repair the skin surgically. Compared with our pediatric TCS patients, our adult patients with TCS who presented with scoliosis and syringohydromyelia did not need to additional surgical intervention, whereas $38 \%$ of our child TCS patients who presented with the same malformations were underwent additional surgery to treat their complaints.

Surgery-related complications included three cerebrospinal fluid (CSF) leakages, three surgical site infections (SSI), and 
one pseudomeningocele. Pseudomeningocele was developed in one female patient 4 years after detethering surgery. All of these patients successfully treated either conservatively or surgically. One patient complained of worsening muscular weakness. Our complications remain less than those of Iskandar et al. (6) who reported that one CSF leakage, five pseudomeningocele, two patients complained of worsening bladder dysfunction, whereas four patients experienced persistent pain and one complained of worsening pain postoperatively.

In the adult population, the rate of retethering has been quoted to be as high as $29 \%(2,3,6,7,15,16)$. Usually recurrent TCS can lead to the same significant complaints that seen in patients before primary surgery. In our series, the retethering rate is $4.3 \%$ which developed in a male patient 6 years later. The patient underwent detethering procedure and complete resection of his lipoma surgically and improved. In this case, the authors noticed that laminoplasty was a good barrier to protect thecal sac and nerve roots from fibrosis and granulation tissues.

\section{Standard Management of TC in Adults}

Almost authors generally, recommend surgery as soon as neurological symptoms were present $(3,5-7,11,12)$. Whereas, there are bit authors recommended surgery for those with progressive neurological symptoms (7). The authors in this paper aimed to describe standard management protocol that they use to treat TC in adults. Despite the initial approach of surgical intervention is aimed at dealing with the pathological conditions that cause the symptoms in symptomatic patients with TCS, the surgical management of asymptomatic TC remains controversial. Therefore, the patients present with suspicious symptoms (back pain, legs pain and/or urinaryfecal incontinence) (Table V) associated with any malformations or structural lesions (such as; lipomyelomeningocele, lipomeningocele, dermal sinus tract, cutaneous stigmata (hypertrichosis), scoliosis or another system malformations (e.g. congenital heart diseases, congenital kidney diseases or genetic syndromes) (Tables II, VI) have to undergo detailed neurological and physical examination, followed by craniospinal MRIs have to be performed. If there are any findings that support TC, the patients have to undergo a urodynamic test. If all investigations lead us to diagnose the patient as symptomatic TCS, the neurosurgeons have to explain the risks, complications and benefits of the surgical intervention for TCS to patients and their families which will help them to make decision about the operative option. If both physicians and patient's family plan to surgery, the neurophysiological monitoring and laminoplasty rather than laminectomy have to be applied. Intraoperative surgical strategies depend on the additional pathological entities that associated with TC. Klekamp recommended that a complete resection, including the capsules in hamartomas (i.e. lipomas, dermoid cysts, epidermoid cysts and neurenteric cysts), and using artificial materials for duraplasty (7). In our series, there were 8 adult TCS patients associated with lipomas, only 3 out of these 8 patients were lipomas resection performed, one patient had recurrence after 6 years even complete resection of lipoma with its capsule had been done. To avoid the serious complications and retethering lipoma was left without resection after the intraoperative evaluation showed that lipoma did not press on nerve roots or dural sac. However, asymptomatic patients have an increased risk of developing new neurological deteriorations. Close patient follow-up and timely treatment for local pathologies after detecting change in urodynamic or manual motor testing may protect patients from new deficits.

The adult TCS patients are less likely to show any neurological deterioration because there has already been rapid spinal column growth in the setting of medulla spinalis that is tethered caudally. Three patients out of our patients did not undergo TC release, just BS resection, one of these three patients underwent cystectomy too (illustrative case 1). The guide here is the consistent all of clinical presentation, neurological examination with urodynamic study. In these three cases, the presenting symptom was pain, while the urodynamic tests showed normocompliant normotonic bladder function with less than $50 \mathrm{ml}$ post-void residual urine (normal). Therefore, BS resection was adequate to resolve their complaints, rather than detethering procedure that could result in new neurosurgical deficits. Thus, our management does not agree with what most authors in the literature who suggested that the TC release procedure was acceptable as a necessary intervention in adult TC patients $(6,7,11,12,17)$.

\section{CONCLUSION}

Neurological deficits developed in TC adult patients are generally irreversible. Therefore, early surgery is recommended in symptomatic patients. Despite the good results obtained from our surgical interventions for symptomatic TCS in adults, the neurosurgeons have not forgotten that tethered cord releasing is complicate procedure and has serious complications. Full neurological and physical examination, craniospinal MRIs, urodynamic test are essential before planning the surgical treatment for TCS. Urodynamic test gives predicts about almost future deteriorations in adult patients with TCS, therefore it is essential before planning surgery.

\section{- REFERENCES}

1. Akay KM, Izci Y, Baysefer A, Timurkaynak E: Split cord malformation in adults. Neurosurg Rev 27: 99-105, 2004

2. Bowman RM, McLone DG, Grant JA, Tomita T, Ito JA: Spina bifida outcome: A 25-year prospective. Pediatr Neurosurg 34: 114-120, 2009

3. Bowman RM, Mohan A, Ito J, Seibly JM, McLone DG: Tethered cord release: A long-term study in 114 patients. J Neurosurg Pediatr 3: 181-187, 2009

4. Cochrane DD: Cord untethering for lipomyelomeningocele: Expectation after surgery. Neurosurg Focus 23(2): E9, 2007

5. Fehlings MG, Arvin B: Editorial. Recurrent tethered cord syndrome: A novel approach for a difficult surgical condition? J Neurosurg Spine 10: 275-277, 2009 
6. Iskandar BJ, Fulmer BB, Hadley MN, Oakes WJ: Congenital tethered spinal cord syndrome in adults. Neurosurg Focus 10 (1): E7, 2001

7. Klekamp J: Tethered cord syndrome in dults. J Neurosurg Spine 15: 258-270,2011

8. Klekamp J, Samii M: Introduction of a score system for the clinical evaluation of patients with spinal processes. Acta Neurochir (Wien) 123: 221-223, 1993

9. Kokubun S, Ozawa H, Aizawa T, Ly NM, Tanaka Y: Spineshortening osteotomy for patients with tethered cord syndrome caused by lipomyelomeningocele. J Neurosurg Spine 15: 21-27, 2011

10. Kural C, Guresci S, Simsek GG, Arslan E, Tehli O, Solmaz I, Izci Y: Histological structure of filum terminale in human fetuses: Laboratory investigation. J Neurosurg Pediatr 13(4): 362-367, 2014

11. Lapsiwala SB, Iskandar BJ: The tethered cord syndrome in adults with spina bifida occulta. Neurol Res 26: 735-740, 2004

12. Lee GY, Paradiso G, Tator CH, Gentili F, Massicotte EM, Fehlings MG: Surgical management of tethered cord syndrome in adults: Indications, techniques, and long-term outcomes in 60 patients. J Neurosurg Spine 4(2):123-131, 2006

13. Phuong LK, Schoeberl KA, Raffel C: Natural history of tethered cord in patients with meningomyelocele. Neurosurgery 50 : 989-995, 2002
14. Rajpal S, Tubbs RS, George T, Oakes WJ, Fuchs HE, Hardley MN, Iskandar BJ: Tethered cord due to spina bifida occulta presenting in adulthood: A tricenter review of 61 patients. $J$ Neurosurg Spine 6: 210-215, 2007

15. Skin P, Halpin RJ, Ganju A, Liu JC: Management of recurrent adult tethered cord syndrome. Neurosurg Focus 29(1):E5, 2010

16. Solmaz I, Izci Y, Albayrak B, Cetinalp E, Kural C, Sengul G, Gocmez C, Pusat S, Tuzun Y: Tethered cord syndrome in childhood special emphasis in the surgical technique and review of the literature with our experience. Turk Neurosurg 21(4):516-521, 2011

17. Stetler WR, Park P, Sullivan S: Pathophysiology of adult tethered cord syndrome: Review of the literature. Neurosurg Focus 29(1):E2, 2010

18. Tehli O, Hodaj I, Kural C, Solmaz I, Onguru O, Izci Y: A comparative study of histopathological analysis of filum terminale in patients with tethered cord syndrome and in normal human fetuses. Pediatr Neurosurg 47: 412-416, 2011

19. Van Leeuwen R, Notermans NC, Vandertop WP: Surgery in adults with tethered cord syndrome: Outcome study with independent clinical review. J Neurosurg 94 Suppl 2: 205-209, 2001

20. Yamada S, Knerium DS, Mandybur GM, Schultz RL, Yamada BS: Pathophysiology of tethered cord syndrome and other complex factors. Neurol Res 26:722-726, 2004 